\title{
Article \\ Relationships between Coerced Sexting and Differentiation of Self: An Exploration of Protective Factors
}

\author{
Jessica Laird ${ }^{1}$, Bianca Klettke ${ }^{1,2, *}$, Elizabeth Clancy ${ }^{1,2}$ () and Ian Fuelscher ${ }^{1}$ \\ 1 School of Psychology, Deakin University, Geelong, VIC 3220, Australia; jjlaird@deakin.edu.au (J.L.); \\ elizabeth.clancy@deakin.edu.au (E.C.); ian.fuelscher@deakin.edu.au (I.F.) \\ 2 Center for Social and Early Emotional Development, Deakin University, Geelong, VIC 3220, Australia \\ * Correspondence: Bianca.Klettke@deakin.edu.au; Tel.: +61-(03)-9244-6207
}

Citation: Laird, J.; Klettke, B.; Clancy, E.; Fuelscher, I. Relationships between Coerced Sexting and Differentiation of Self: An Exploration of Protective Factors. Sexes 2021, 2, 468-482. https://doi.org/10.3390/sexes2040037

Academic Editors: Joana Carvalho and David L. Rowland

Received: 10 August 2021

Accepted: 2 November 2021

Published: 8 November 2021

Publisher's Note: MDPI stays neutral with regard to jurisdictional claims in published maps and institutional affiliations.

Copyright: () 2021 by the authors. Licensee MDPI, Basel, Switzerland. This article is an open access article distributed under the terms and conditions of the Creative Commons Attribution (CC BY) license (https:// creativecommons.org/licenses/by/ $4.0 /)$.

\begin{abstract}
Pressure to send sexually explicit messages, or 'sexting coercion' is associated with adverse mental health outcomes and sexual risk behaviors. This study explores Differentiation of Self (DoS) as a potential protective factor to reduce susceptibility to sexting coercion. A convenience sample of 399 Australian participants, aged 18 to 21 years $\left(M_{\text {age }}=19.63 ; S D=1.14,68.2 \%\right.$ women $)$ completed an online survey measuring sexting behaviors and DoS. Women were four times more likely to send willing unwanted sexts, and seven times more likely to engage in coerced unwanted sexting than men. Participants with low DoS were four times more likely to engage in coerced unwanted sexting. DoS significantly mediated the relationship between gender and coerced unwanted sexting. Results support the proposal of a sexting coercion typology encompassing discrete sub-types of sexting coercion. Results also indicate DoS may operate as a protective factor for young people in Australia, reducing compliance with sexting when coerced.
\end{abstract}

Keywords: sexting coercion; differentiation of self; protective factors

\section{Introduction}

The digital age has drastically altered the expression of human relationships, with sexting behaviors described as an extension of normative social interactions, including sexual exploration and behavior [1,2], and similarly converging across technology-facilitated forms, including sexting coercion. While there is no universally agreed upon definition for 'sexting' or 'sexting coercion', most research defines 'sexting' as the electronic exchange of sexually explicit text messages, images, photos, or video content via any digital platform [1-3]; whereas 'sexting coercion', constitutes an aggressive and violent form of sexting behavior, occurring amid threat, pressure, persistent requests, and/or coercion [2,4]. Research frequently uses the umbrella term 'sexting coercion' to comprise both consensual and coercive aspects of the behavior [4-6]; however, broad and ambiguous definitions may contribute to inconsistent and mixed findings [7]. For example, some research refers to sexting coercion as 'pressured sexting', measured by indicating the presence of external or internal social pressures, resulting in sexting compliance [6]. In contrast, 'unwanted consensual sexting' is a term adapted from explanations of unwanted but consensual sex, and is used to describe an individual who consensually engages in sexting despite not wanting to [8]. However, few studies differentiate between individuals who engage in unwanted sexting with or without consent, or willingness [8-10]. Moreover, despite 'unwanted consensual sexting' denoting a level of consent to sext, this term does not clearly account for the existence of social pressures which may influence willingness to engage in sexting [8]. A lack of delineation and definition between coercive sexting conceptualization and measurement may hinder the advancement of sexting research by creating difficulties when attempting to compare or synthesize data, limiting the capacity for research to compare findings across populations 
Sexting coercion can include sending (e.g., sending an unwanted or non-consensual sext amid pressure, threat or coercion, and/or the dissemination of sexual content of a person without their consent) and receiving (e.g., receiving and being forcefully exposed to sexual content via image, photo, text, or video without consent) sexts. While research suggests that consensual sexting can be a healthy and normative expression of sexual development [11], coerced and unwanted sexting has been associated with harms, such as sexual exploitation [12], exposure to extortion, online grooming, cyberbullying, suicidal attempts, depressive symptoms, intimate partner violence [4], child pornography distribution [13], emotion dysregulation [14], and other forms of technology-facilitated sexual violence $[15,16]$.

Prevalence rates across multiple studies sampling young people aged 14 to 30 years indicate that between $12-70 \%$ of respondents have reported feeling pressured and/or coerced to sext [1,17]. Sexting coercion may also function as an extension of offline forms of sexual coercion [7], with associated gender differences; for example women indicate feeling pressured or forced to sext up to six times more often than men [18-20], and adolescent women who experience physical sexual coercion are more likely to engage in sexting behaviors [7]. Finally, while $96 \%$ of young people use personal smartphones daily [21], the COVID-19 pandemic and its associated lockdowns and social distancing has increased technology-mediated sexual interactions [22], yet despite serious outcomes associated with sexting coercion, the exploration of protective factors which may mitigate risks remains limited.

\subsection{Concepetualising Sexting Coercion}

To contribute toward a comprehensive and unified conceptualization of sexting coercion, we are adapting a model of unwanted sexual intercourse developed by Morgan, Johnson, and Sigler [21] to unwanted sexting. This original model was chosen due to its delineation of unwanted sexual intercourse across three categories, including forced, coerced, and willing [21] (p. 516). Forced sexual intercourse is defined as involving physical force, whilst coerced sexual intercourse involves non-physical force and pressures such as threats, dishonesty, and/or false enticements. Importantly, unwanted sexual intercourse can also be willing, whereby the person consents but did not want to engage in the sexual activity.

Adapting this model to the online sexual behavior of unwanted sexting, three categories of unwanted sexting can be identified: forced unwanted sexting, coerced unwanted sexting, and willing unwanted sexting (see Figure 1). The categories within the sexting coercion model addresses three types of sending a sext, which may result in sexting coercion. Although non-consensual dissemination of private sexts is a type of sending involved in sexting coercion, this is not included in our model due to its focus on perpetration. Legal frameworks purport that coercion need not involve physical force, and that force can be both physical and psychological. 'Forced unwanted sexting' may occur in the context of threatening harm to a victim or their family, or denying an individual autonomy or equality in a context of chronic power imbalance that is exploited by a perpetrator [23]. Due to the online nature of the behavior, forced unwanted sexting, involving physical force, is a possible, but potentially less frequent behavior. However, the categories of coerced unwanted sexting and willing unwanted sexting are critical distinctions. Research findings suggest women may consent to unwanted sex as a form of compliance due to gender socialization $[23,24]$; however, limited research explores why or if the same willingness despite not wanting to occurs in sexting behaviors. While coerced unwanted sexting represents respondents feeling pressured or coerced to send a sext message, willing unwanted sexting represents consenting to sending a sext but not wanting to. Coerced unwanted sexting may involve the use of coercive control, where abuse tactics are designed to limit a victim's decision-making, using privileged knowledge of a victim's vulnerabilities to control them, including tactics such as micro-regulation, manipulation, and isolation [23]. Considering the conceptual overlap of sexting coercion with sexual coercion and the substantial evidence that women frequently experience unwanted sex under nonviolent duress 
from partners [25], the willing unwanted sexting subtype represents a sexting behavior which is not characterized by force, coercion or threat, but perhaps the more insidious societal external and internal pressures which motivate individuals to comply with requests despite not wanting to, to attain approval, avoid rejection, or to maintain societal norms or relationship status [26,27]. Distinguishing between coerced unwanted sexting, based on pressure, and willing (or consensual) unwanted sexting may extend prior literature and increase understanding of the nuances identified across sexting coercion research.

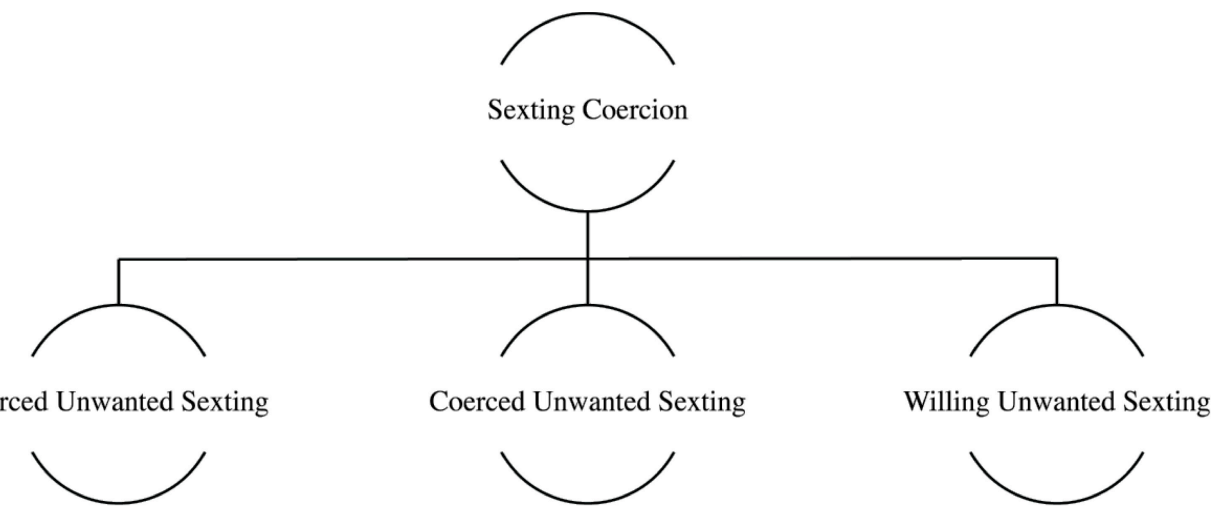

Figure 1. Categories of sexting coercion. Note: Adapted from [23].

\subsection{Sexting Coercion and Gender}

Research has pointed to gender differences with regards to the motivations and consequences of sexting coercion $[21,25]$. Studies have shown that women send willing unwanted sexts more frequently than men [4] as an extension of flirting or foreplay [9], out of felt responsibility for relationship maintenance and sexual compliance [8]. As such, the sending of willing unwanted sexts can occur in response to perceived negative relational consequences, such as intimate partner disapproval or conflict, or threats to commitment [18]. Consequently, sexting coercion has been described as a component of intimate partner violence [4]. Men however, report experiencing pressure to sext as a form of attaining peer (not partner) approval [26], or arising from a fear of social exclusion [27]. There are also gender differences in the social consequences for engagement in sexting, whereby men report receiving esteem and popularity for sexting [15], whilst women often report shame and victim-blaming [27]. Although early research indicates sexting coercion may replicate gender inequities found in violence against women [25], coerced unwanted sexting and willing unwanted sexting remain conflated and undistinguished amongst existing evidence. Furthermore, sexting coercion research is limited in being almost exclusively conducted with heteronormative and cisgendered samples, hence limiting any extension to diverse genders or sexualities.

\subsection{Sexting Coercion and Self-Regulation}

Research has associated maladaptive self-regulatory mechanisms with increased risk of engaging in coercive sexting [8,14,28-30]. Self-regulatory mechanisms operate by adjusting emotions in response to social demands [31]. Maladaptive self-regulatory patterns manifest in sexting as compliance with external pressures to avoid conflict or negative emotion, satisfy sexual or emotional intimacy, and maintain emotional control $[8,29,32-35]$. While research shows that sending consensual sexts is not associated with poor psychosocial health, being pressured to send sexts is associated with depression, anxiety and emotion dysregulation, indicating that young people with difficulties regulating emotions are at an increased risk of experiencing cyber dating abuse, including sexting coercion $[14,28]$. Sending coerced unwanted sexts has also been associated with higher levels of suicidality, psychosocial stress, and low self-esteem [1,36]. Given these serious consequences, it may be beneficial to identify protective factors to inform preventative measures against sexting coercion. While it is imperative to note that abuse such as sexting 
coercion remains the sole responsibility of offenders, strengthening protective factors in young people and families could promote healthy development, wellbeing, and sexual safety. which may mitigate risk.

One such protective factor which may reduce sexual risk and develop emotion regulation skills is the Differentiation of Self (DoS), a modifiable construct defined as the capacity to balance the emotional and intellectual self (i.e., emotion and self-regulation, acting thoughtfully under stress) and others (i.e., intimacy and autonomy in relationships) [37-41]. Bowen family systems theory is regarded as a comprehensive explanation of psychological health from a systemic perspective, which is heavily embraced in the field of family therapy [42]. Bowen understood that human behavior is influenced and shaped by the need for both autonomy and relational connection, and therefore emotion regulation is conceptualized in the context of the processes of relationships [38-43]. A fundamental component of Bowen theory includes the differentiation of self from the family and the emotional systems which regulate relationships [38-43]. DoS itself comprises four sub-constructs, including I-position (i.e., the capacity to maintain a sense of self amongst others), Fusion (i.e., emotional over-identification with others), Emotional Cutoff (emotional distance) and Emotional Reactivity (the ability to remain calm in response to the emotions of others) [41].

Prior research has implicated DoS as a protective factor against sexual difficulties (e.g., difficulties with sexual drive, function, desire, arousal, and physical or psychological responses to intimacy, pain, and pleasure) and multiple psychosocial stressors, particularly within interpersonal relationships $[42,43]$. Additionally there is evidence that emotion dysregulation increases the risk of engaging in sexting coercion [28]. In contrast, individuals with high DoS report greater capacity to maintain a sense of self in the presence of intimate others, emotion regulation, and increased resistance to external stressors, such as social pressures $[43,44]$. Furthermore, DoS has been found to be associated with a decrease in the experience of relationship violence for women [45]. In contrast, individuals with low DoS who experience equivalent stressors report sexual difficulties, diminished coping and self-regulation, a poorly defined sense of self, and increased sexual compliance [46]. Intervention research shows that DoS can be increased through intervention, including rational, behavioral, and emotive therapy, and person-centered therapy $[47,48]$.

It has been shown that greater DoS reduces emotional fusion, that is, acquiescence to another person in order to regulate their anxiety and emotional distress [39]. Further, increased DoS has been associated with reduced behavioral compliance to others, and boosting individual capacity to reject unwanted requests amidst social pressures [44]. Thus, increasing DoS may reduce engagement in sexting coercion, by strengthening individual capacity to maintain a sense of self amid internal pressures (e.g., emotion dysregulation) and external pressures (e.g., peer/social pressures) [8,44]. Sexting is a prevalent social behavior, peaking during the vulnerable formation of identity in youth [9]. However, very little research has explored protective factors for young people in relation to harmful aspects of sexting behaviors. Key research questions remain as to whether DoS is associated with sexting behaviors, and whether DoS could serve as a protective factor against sexting coercion.

\subsection{Study Aims}

This study extends sexting coercion research by exploring the relationship between sexting coercion behaviors and emotion dysregulation, via Differentiation of Self as a potentially modifiable protective factor. Furthermore, this study seeks to advance the conceptualization and measurement of the sexting coercion construct. The first aim was to investigate the relationship between individual levels of DoS, with both sub-constructs of sexting coercion (willing unwanted and coerced unwanted), within a population of young people. The second aim was to examine the relationship between gender and DoS, and explore whether willing unwanted and coerced unwanted sexting were distinct variables. This study proposes four hypotheses: 
1. Women would be more likely to experience coerced unwanted and willing unwanted sexting than men;

2. Low DoS would be associated with an increased likelihood of experiencing coerced unwanted and willing unwanted sexting;

3. DoS would mediate the relationship between gender and coerced unwanted sexting and willing unwanted sexting; and,

4. Coerced unwanted sexting and willing unwanted sexting are associated with each other.

\section{Materials and Methods}

\subsection{Participants}

In total, 825 participants commenced the survey. Many responses were outside of the inclusion criteria of being aged between 18 and 21 years old, and residing within Australia. Data cleaning resulted in the exclusion of 141 respondents beyond the target age range, 221 respondents with incomplete answers, and 64 respondents residing outside of Australia, leaving an analytical sample of 399 participants. This analytical sample included 272 women $\left(M_{\text {age }}=19.50 ; S D=1.14\right)$ and 127 men $\left(M_{\text {age }}=19.91 ; S D=1.11\right)$ recruited via convenience sampling, identifying as heterosexual $(78 \%)$, homosexual $(4 \%)$, bisexual $(13 \%)$, and other (5\%).

\subsection{Procedure}

Ethics approval was granted by Deakin University Human Research Ethics Committee (Application no. HEAG-H 96_2012). An online questionnaire was distributed in July 2017, via personal social media sites (e.g., Facebook, Instagram) and paper advertisement at consenting institutions (e.g., affiliated universities and sporting clubs). A non-probability sampling method (snowball sampling, where participants were encouraged to share the link further with their own networks) was used, maximizing access to participants [49]. Potential participants were directed to a website to read a brief study description, and provide their consent, prior to completing the online questionnaire. Survey completion took approximately $20-25 \mathrm{~min}$, and participation was voluntary. No incentives were offered for participation. All data were gathered in Australia in July-August 2017. The research team was from the School of Psychology, a department which has a predominantly female undergraduate enrolment, therefore the research team's initial access to participants were from within their own field, which may explain the larger proportion of young women to young men in the sample.

\subsection{Measures}

Coerced Sexting: The Sexting Questionnaire (SQ) measured self-reported sexting behaviors and was developed by the $<$ Blinded for Review $>$ University Sexting Research Group (see Supplementary S1). The SQ is part of a larger study comprising ten subscales; additional data collected but not pertinent to this study included sexting distribution, objectification, personality, and pornography. The SQ included participant demographics (e.g., age, gender, and sexual identity), and dichotomous ("yes" or "no") and Likert scale items ("strongly agree" to "strongly disagree"). Please find a full record of the SQ in Supplementary S1. All questions regarding sexting referred to sexually explicit (i.e., nude or semi-nude) pictures and images. Examples of general sexting items included, "have you ever sent sexually explicit images of yourself via text message or a mobile app" ("yes" or "no"), and "how many times have you sent sexts (as defined above)", (1-2, 3-5, 6-10, 11-25, or $>25$ times). To measure willing unwanted sexting, the following item was used: "Have you ever consented to sexting (sent a sexually explicit image via text or mobile app) when you actually did not want to sext?" Participants were also asked "If you have sent sexually explicit images of yourself via text or mobile app to another person, what was the reason/s?" The response "because you felt pressured to do so" used to identify coerced unwanted sexting. The questionnaire was reviewed with a small focus group $(N=6)$ of young adult participants to test face validity of item wording. 
Differentiation of Self: The Differentiation of Self Inventory-Short Form (DSI-SF [41] comprises four subscales; I-Position, Fusion with Others, Emotional Cutoff and Emotional Reactivity. Two subscales (I-Position and Fusion) were included in this study to reflect current sexting research (i.e., self-regulation and social pressures) [29]. The Fusion and I-Position subscales comprise five items each [41]. Fusion represents emotional overidentification with others (sample item: "whenever there is a problem in my relationship, I' $m$ anxious to get it settled right away"), and I-Position measures capacity to maintain a sense of self (sample item: "I usually do not change my behavior simply to please another person"). One additional item from the original DSI was included, based on theoretical relevance with sexting coercion research (i.e., "I am able to say no to others even when I feel pressured by them") [50]. Responses were measured on 6-point Likert scales, ranging from 1 (not at all true of me) to 6 (very true of me). The DSI-SF has been previously been found to be psychometrically sound (I-Position: $\alpha=0.83$; Fusion: $\alpha=0.74$ ) [50]. Internal consistency indicated sound psychometric properties across the subscales in this study (I-Position: $\alpha=0.80$; Fusion: $\alpha=0.60$ ), consistent with prior studies [51].

\subsection{Data Analysis}

A cross-sectional survey design was implemented for this study, with all data cleaned and tested for assumptions prior to analyses. Casewise diagnostics indicated no missing values. One univariate outlier was found on the Fusion subscale, and recoded back to 3.29 standard deviations above the mean [52]. No multivariate outliers were identified. Continuous scores on the DoS subscales were normally distributed, as per examination of Q-Q plots. Bonferroni correction was used to correct for multiple comparisons [53]. Chi-squared tests of association and logistic regression analyses were conducted to examine relationships between dichotomous variables, including gender, sexting, and DoS. Descriptive statistics were used to describe sexting behaviors and scale distributions. DoS subscales were normally distributed at each level of the sexting outcome variables and for the I-Position subscale, as assessed by Shapiro-Wilk's test $(p>0.05)$. The Fusion subscale was moderately skewed $(z=3.7)$; however, a square root transformation rectified this, and distributed the frequencies normally. As point-biserial correlations and phi coefficients are special cases of Pearson's $r$, effect sizes are considered as follows; small: $r=0.10$, medium: $r=0.30$, and large: $r=0.50$ [54]. Effects sizes for odds ratio (OR) were determined via Cohen's d calculations, indicating small: $\mathrm{d}=0.20$ when $\mathrm{OR}>1.68$; medium: $\mathrm{d}=0.50$ when OR > 3.47; and large: $d=0.80$ when $O R>5$ [55]. The final step was to conduct a parallel multiple-mediation to examine the proposed conceptual model with DoS (I-Position and Fusion) as potential mediators between gender and sexting coercion (see Figure 2). A series of regression analyses were performed, with bootstrap samples used to calculate bias corrected confidence intervals around direct and mediated effects [56,57]. All analyses were conducted in SPSS version 24 [58], and utilized the macro PROCESS [59]. 


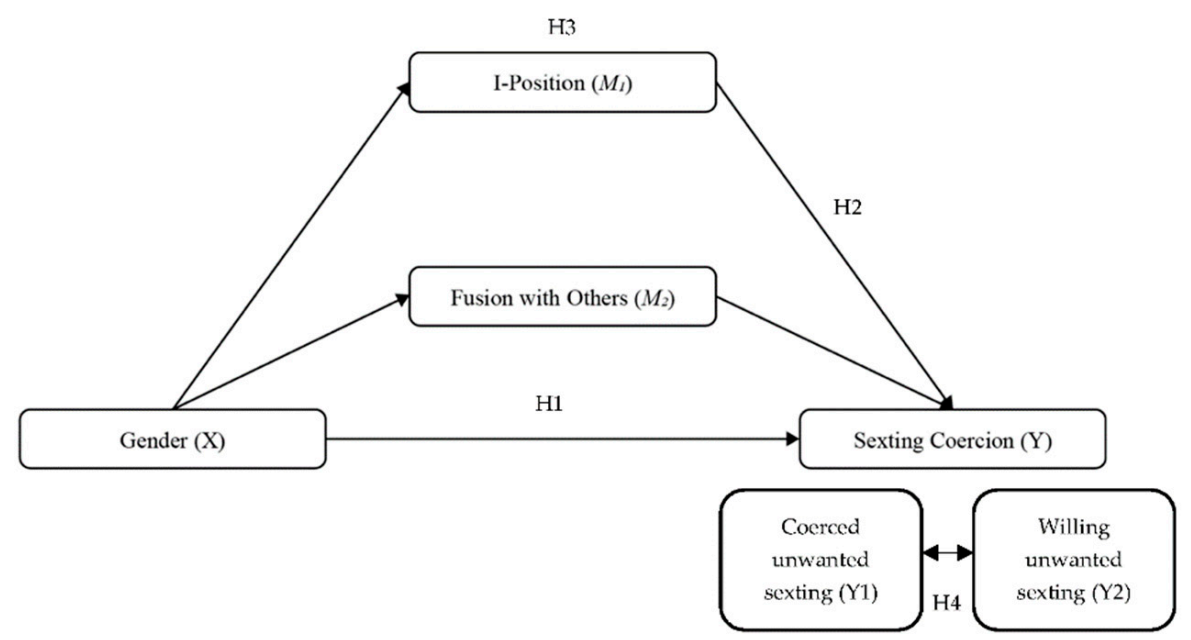

Figure 2. Conceptual model: parallel multiple mediation testing I-Position and Fusion as mediators of gender on sexting coercion variables.

\section{Results}

\subsection{Descriptive Statistics}

Of the 399 respondents, the majority reported having sent a sext (74\%); a quarter indicated sending a willing unwanted sext $(23 \%)$; and one in eight respondents reported sending a coerced unwanted sext $(12 \%)$. Overall, women reported sending sexts more frequently than men, $t(292)=8.9, p<0.01$. Men reported higher scores across both DoS subscales (I-Position: $t(397)=3.30, p=0.001, d=0.36$; Fusion: $t(397)=3.25, p=0.001$, $d=0.34$ ) compared to women, with small significant effect sizes [51]. Descriptive statistics and measurement of internal consistency across DoS subscales are presented in Table 1.

Table 1. Descriptive statistics and internal consistency of DoS subscales.

\begin{tabular}{cccccc}
\hline DoS Subscale & M & (SD) & Range (Min, Max) & N & $\alpha$ \\
\cline { 1 - 1 } Dichotomized Subscales & & & & & \\
\cline { 1 - 1 } Low I-Position & 20.47 & $(4.17)$ & $(7,26)$ & 187 & \\
High I-Position & 31.00 & $(4.16)$ & $(27,42)$ & 213 & \\
Low Fusion & 8.65 & $(1.82)$ & $(5,12)$ & 197 & \\
High Fusion & 15.24 & $(2.89)$ & $(13,25)$ & 203 & \\
Continuous Subscales & & & & & \\
\cline { 1 - 1 } I-Position (Female) & 25.93 & $(7.26)$ & $(7,42)$ & 272 & 0.80 \\
I-Position (Male) & 28.48 & $(7.08)$ & $(9,42)$ & 127 & \\
Fusion (Female) & 11.44 & $(3.86)$ & $(5,25)$ & 272 & 0.60 \\
Fusion (Male) & 12.87 & $(4.63)$ & $(5,25)$ & 127 & \\
\hline
\end{tabular}

Note: $\mathrm{M}=$ mean, $\mathrm{SD}$ = standard deviation, $\alpha=$ Cronbach's Alpha.

\subsection{Sexting Coercion and Gender}

To assess Hypothesis One, that women would be more likely to experience sexting coercion than men, chi-squared tests for independence were conducted, revealing women were significantly more likely to experience both coerced unwanted $(15.8 \%), \lambda^{2}(1,399)=15.35$, $p<0.000$, and willing unwanted sexting $(29.0 \%), \lambda^{2}(1,399)=12.91, p<0.001$, compared to men ( $2.4 \%$ and $12.6 \%$ respectively). Similarly, logistic regression analyses revealed that women were 6.3 and 2.8 times more likely to exhibit coerced unwanted sexting and willing unwanted, respectively, when compared to men (see Table 2). 
Table 2. Associations between sexting coercion variables and gender.

\begin{tabular}{|c|c|c|c|c|}
\hline \multirow{4}{*}{$\begin{array}{l}\text { Predictor } \\
\text { Variables }\end{array}$} & \multicolumn{4}{|c|}{ Outcome } \\
\hline & \multicolumn{4}{|c|}{ Variables } \\
\hline & \multicolumn{2}{|c|}{ Coerced Unwanted Sexting } & \multicolumn{2}{|c|}{ Willing Unwanted Sexting } \\
\hline & $b$ (S.E) & Odds Ratio [95\% CI] & $b$ (S.E) & Odds Ratio $[95 \% \mathrm{CI}]$ \\
\hline Gender ${ }^{1}$ & $1.84(0.53)$ & $6.30[2.22,17.81]^{* *}$ & $1.05(0.28)$ & $2.85[1.64,4.93]^{* *}$ \\
\hline
\end{tabular}
deviation, ${ }^{* *} p \leq 0.01, p \leq 0.001 ; n=399 .{ }^{1} \operatorname{Ref}$ (women).

\subsection{Sexting Coercion and Differentiation of Self}

To investigate Hypothesis Two, whether low DoS is associated with an increased likelihood of experiencing coerced unwanted and willing unwanted sexting, two logistic regression analyses were performed with Fusion and I-Position as predictors, and coerced unwanted and willing unwanted sexting as dependent variables respectively (i.e., sent a sext, "yes" or "no"). Tests of the full models were statistically reliable for coerced unwanted sexting $\left(\chi^{2}\right.$ FullModel $\left.(2,399)=25.02, p<0.001\right)$, and willing unwanted sexting $\left(\chi^{2}\right.$ FullModel $(2$, $399)=7.72, p=0.021$ ), indicating that I-Position and Fusion reliably distinguished between engaging in both sexting coercion behaviors. $R^{2}$ is reported to present an estimate of overall model performance, with Fusion and I-Position included in the model together, finding that coerced unwanted $\left(R^{2}=0.10\right)$, and willing unwanted sexting $\left(R^{2}=0.18\right)$ account for a small proportion of variability. Prediction success was moderately impressive, with $88.7 \%$ of individuals sending a coerced unwanted sext versus not sending a sext correctly predicted, and $76.2 \%$ of individuals sending a willing unwanted sext versus not sending a sext correctly predicted. Young people with higher I-Position (OR $=0.91,95 \%$ CI: $0.87,0.95)$ and lower Fusion (OR $=0.81,95 \%$ CI: $0.81,0.97)$ were significantly less likely to engage in coerced unwanted sexting. Young people with higher I-Position (OR $=0.96,95 \%$ CI: 0.93 , 0.99 ) were significantly less likely to engage in willing unwanted sexting; however, Fusion $(\mathrm{OR}=0.95,95 \%$ CI: $0.90,1.01)$ did not significantly predict willing unwanted sexting.

\subsection{Gender and Sexting Coercion Mediated by Differentiation of Self}

Hypothesis Three proposes DoS would mediate the relationship between gender and coerced unwanted sexting and willing unwanted sexting. Baron and Kenny's (1986) pre-conditions and assumptions [60] were satisfied for coerced unwanted sexting, but not for willing unwanted sexting. Therefore, the proposed model was tested with gender as a predictor of unwanted coerced sexting, mediated by I-Position and Fusion (Figure 3).

A series of linear and logistic regression analyses tested the proposed mediation model $[59,61]$. Examination of parameter estimates (Table 1) found that gender was a significant predictor of the mediators I-Position $\left(a_{1}=-2.56\right)$, and Fusion $\left(a_{2}=1.44\right)$; and both I-Position $\left(b_{1}=-0.09\right)$ and Fusion $\left(b_{2}=-0.11\right)$ were significant predictors of coerced unwanted sexting. Secondly, gender was a significant predictor of experiencing coerced unwanted sexting $(c=2.05, p<0.01)$, consistent with partial mediation [59]. Finally, bias corrected bootstrap confidence intervals with 10,000 bootstrap samples was used to test the effects of gender on coerced unwanted sexting, through the potential mediators [57]. When including I-Position in the model, the association between gender and coerced unwanted sexting reduced by 0.22 units $\left(a_{1} b_{1}=0.22, S E=0.09\right.$, BCa 95\% CI: $\left.0.08,0.47\right)$. When Fusion was included in the model, the association between gender and coerced unwanted sexting reduced by 0.17 units $\left(a_{2} b_{2}=0.17, S E=0.09, \mathrm{BCa} 95 \% \mathrm{CI}: 0.03,0.39\right)$. This suggests that I-Position and Fusion significantly mediated the relationship between gender and coerced unwanted sexting in the proposed model. To ascertain effect sizes, and relative to sample size $(N=399), R^{2}$, as recommended by [62] and [63], was used. While little variance in I-Position or Fusion was explained by gender alone $\left(R^{2}=0.03\right)$, nearly a fifth of the variance in coerced unwanted sexting was accounted for by the proposed mediators and gender $\left(R^{2}{ }_{N}=0.18\right)$, with a small but significant effect size [64]. Overall results indicate 
that conditions for partial mediation were satisfied, revealing DoS as a significant mediator of the relationship between gender and coerced unwanted sexting.

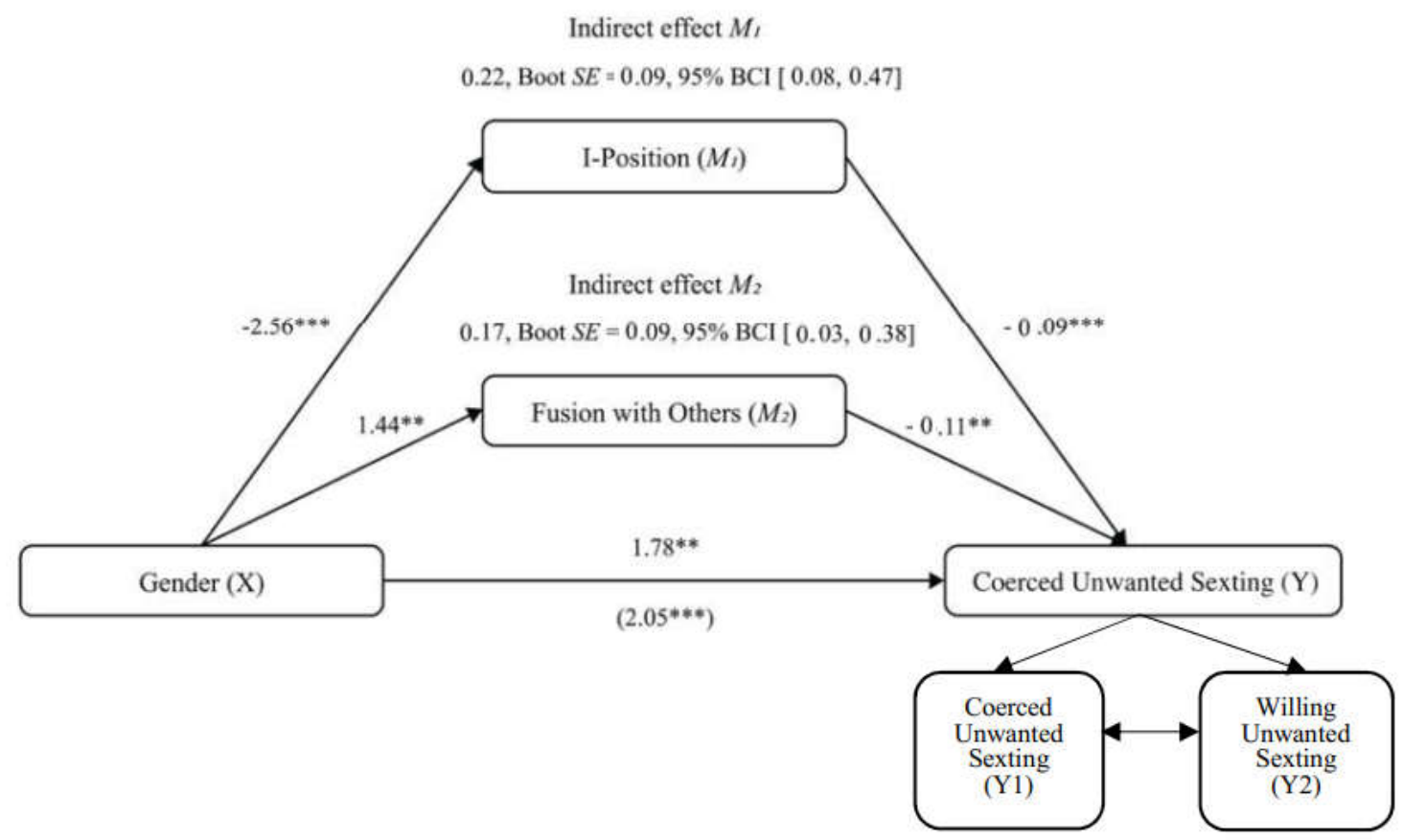

Figure 3. Parallel multiple mediation model testing I-Position and Fusion as mediators of the effects of gender on coerced unwanted sexting. Note: Parallel multiple mediator model for the relationship between gender and coerced unwanted sexting, mediated by I-Position and Fusion (DoS). Total effects in parentheses. All coefficients unstandardized [59] BCI: bias corrected confidence interval; 10,000 bootstrap samples. Gender (ref = women); Coerced unwanted sexting $(r e f=$ yes $)$. ${ }^{* *} p<0.01,{ }^{* * *} p<0.001$.

\subsection{Willing Unwanted Sexting and Coerced Unwanted Sexting}

Hypothesis Four proposed that coerced unwanted sexting and willing unwanted sexting would be associated with each other. A full model against a constant-only model indicated that coerced unwanted sexting significantly predicted willing unwanted sexting $\left(\chi^{2}(1)=115.23, p<0.001\right)$; indicating that those who responded "yes" to sexting when coerced, despite not wanting to, were 42 times more likely to experience willing unwanted sexting, when compared to those who indicated "no" (OR $=41.86,95 \%$ CI: 17.15, 102.15). Based on the overall model fit as described by Nagelkerke R-squared, a substantial proportion of variability in coerced unwanted sexting was not accounted for by the model $\left(R^{2}{ }_{N}=0.33\right)$. Although coerced unwanted and willing unwanted sexting have been used interchangeably throughout the literature, the significant association between the two variables indicates that, while they have partial overlap, factors other than willing unwanted sexting explains differences in coerced unwanted sexting.

\section{Discussion}

In order for prevention programs to stop violence before it begins, a clear understanding of the complex interplay between individual, relationship, and societal factors is critical. The current-evidence base presents broad and ambiguous definitions of sexting coercion $[1,2]$. Use of a more narrow and comprehensive understanding of sexting coercion may allow for improved measurement of specific sexting coercion behaviors, and maximize how findings can pinpoint the scope and direction of prevention and intervention efforts. Furthermore, very few studies explore protective factors which may prevent against serious harm. This was the first empirical study to explore the relationship between sexting coercion as a form of violence, gender, and Differentiation of Self as a potential 
protective factor in a cohort of young people. The DoS construct was utilized to measure an individual's capacity to engage in emotion regulation and maintain a sense of self amid relationships, with the intent to examine its value as a protective factor which may reduce sexting coercion risk.

Hypothesis One (i.e., that young women would be more likely to experience sexting coercion than young men) was supported, with women being seven times more likely to send a coerced unwanted sext, and three times more likely to send a willing unwanted sext than men $[4,65]$. This is consistent with findings that suggest digital interactions replicate existing offline gender inequities, and therefore at the societal level, sexting coercion may be an extension of violence against women $[4,6,34,66]$.

Mixed findings emerged from Hypothesis Two, demonstrating that low I-Position and Fusion, characterized respectively by diminished capacity to maintain a sense of self in relationship, and emotional over-identification with others, increased the likelihood of sending an unwanted sext when coerced or pressured by four times. Similar to prior findings of associations between willing unwanted sexting and avoiding conflict or anxiety [5], a small significant relationship was found between I-Position and willing unwanted sexting. However, no relationship was found between Fusion and willing unwanted sexting, indicating that at the individual level, a strong sense of self may be more important as a protective factor against sexting coercion risk than guarding against emotional fusion. This is consistent with prior results, which suggest that young women with a stronger sense of self are less likely to experience relationship violence [45,67].

Hypothesis Three predicted that DoS would mediate the relationship between gender and coerced unwanted sexting, therefore a conceptual model in which DoS (Fusion and I-Position) mediates the relationship between gender and coerced unwanted sexting was tested. As expected, the relationship between gender and coerced unwanted sexting was mediated by both the DoS variables I-Position and Fusion. This suggests that a strong sense of self at an individual level may play a role in reducing the impact of societal pressures sexting compliance for young women. Therefore, DoS may act as a potential protective factor, reducing a young person's vulnerability to coerced unwanted sexting.

Finally, as per Hypothesis Four, which proposed coerced unwanted sexting and willing unwanted sexting would be associated with each other, respondents who reported coerced unwanted sexting were 42 times more likely to send a willing unwanted sext. Although it makes intuitive sense that coerced unwanted sexting and willing unwanted sexting share some degree of commonality across sexting coercion as a concept, willing unwanted sexting only explains a third of the variance in coerced unwanted sexting in this study. Therefore, this discrepancy indicates that, while despite willing unwanted sexting and coerced unwanted sexting are overlapping constructs, they may tap into unique aspects of the sexting coercion construct, and importantly, may not be analogous. That is, although both sexting coercion variables are 'unwanted', coerced unwanted sexting includes perceived coercion or pressure from an external source (e.g., repeated requests, threat, or manipulation). Results highlight that further research is warranted to examine how individual variables map onto the overall sexting coercion construct. Individuals sending a willing unwanted sext may not perceive these same overt pressures or coercion and send the sext willingly, perhaps in response to more nuanced pressures, such as gender socialization or other relationship inequalities. Furthermore, given existing research which classifies sexting coercion within the intimate partner violence construct [4], online sexual victimization [68], or technology-facilitated sexual violence [69], our findings support the proposed model in Figure 1 which suggests that sexting coercion encompasses discrete subtypes of sexting, including forced unwanted sexting, coerced unwanted sexting, and willing unwanted sexting. Similar to other forms of sexual violence, elements of pressure and coercion overlap and interconnect across levels of individual and sociocultural influences, highlighting the complexities involved in evaluating sexting coercion patterns $[9,26]$.

Overall current findings advocate for a nuanced understanding of coerced unwanted sexting and willing unwanted sexting, suggesting that these variables deserve cautious 
attention in future research measurement and interpretation. Furthermore, this study suggests that augmenting DoS may mitigate risks associated with the effects of social and individual factors associated with sexting coercion, by mediating vulnerabilities faced by young people. In particular, a stronger sense of self is likely to act as a protective factor, reducing the likelihood of complying with pressure to send coerced unwanted sexts. Considering that previous research has indicated that one in five respondents who sext experience coercion, pressure or threat to do so [8], current findings hold unique implications for the prevention of sexting coercion.

\subsection{Implications for Practice}

Although the ubiquity of digital communications, including sexting in general, can be perceived as a normalized exploratory behavior, sexting coercion reveals consistent links associated with risk linked to gender, positioning young women from adolescence to emerging adulthood as most at risk [5,33]. Direct associations between sexting coercion and negative outcomes, including depression, psychological trauma, and sexual coercion, ref. [4] compel further empirical exploration of protective factors.

Furthermore, successful violence prevention programs are informed by both risk and protective factors [70]. DoS offers one such potential protective factor, which may increase a young person's ability to respond safely to sexual experiences, by developing capacity to maintain a sense of self and emotion regulation amid relational and sociocultural pressures $[9,14,29]$. It is crucial to reiterate that all abuse culpability remains the responsibility of perpetrators alone. Nevertheless, it is important for intervention and prevention programs to consider how to overcome the current gender inequality zeitgeist, and minimize potential harms. As such, DoS may be a relevant focus in developing programs which empower young people to relate safely within the digital realm. Current preventative programs tend to either focus on risk or protective factors, with few incorporating both [70]. Additionally, risk frameworks targeting respectful relationships within school-based programs tend to focus on cognitive understandings of gender, power, and violence, whilst often failing to address the impacts of digital violence altogether $[19,71]$.

With gender inequalities posing particular lifelong harm to the sexual and reproductive health of adolescent girls [72], early identification of vulnerability may prevent harm from sexting coercion occurring. Identification of DoS sub-constructs may contribute to preventative frameworks by enabling early identification of sexting coercion vulnerability, through the assessment of interpersonal and emotional strengths, such as a sense of self or emotional fusion [46]. Affording opportunities for professionals to engage with young people to provide education regarding social norms, healthy relationships, and awareness of violence, using non-shaming or non-blaming methods before harm occurs. Future research investigating the development of preventative models, which target mitigation of sexting coercion, may benefit from further examination of protective factors, such as DoS.

Finally, this paper's contribution to the conceptualization of sexting coercion constructs may assist in the delineation and definition of coerced unwanted and willing unwanted sexting subtypes, progressing clarity for researchers and maximizing the capacity to contrast and synthesize consistent and comparable data. The implications of a clearly defined construct of sexting coercion enables researchers, policies, laws, education, and social services to share a common understanding of the issue, which can empower the progress of preventive and intervention efforts.

\subsection{Limitations and Direction for Future Research}

Although this study contains promising findings for future research, several limitations should be acknowledged. Firstly, some significant effects were small in magnitude [64], therefore results should be interpreted carefully. Future research might address this limitation by utilizing more extensive measures of the outcome variables. Sexting coercion is highly nuanced, occurring within a cohort where executive functioning and identity are just being forged, alongside a rapidly changing digital age; therefore, sexting 
coercion behaviors are complex, and explanations are likely to be an interaction of many variables. Secondly, this study utilized a self-selected convenience sample, and, as such, it is possible that active participants in online cultures were over-represented, limiting the generalizability of these results. Self-selection bias is also possible, if participants were inclined to volunteer because they were more open to discussing sexting. The smaller cohort of men, consistent with other sexting studies, also indicates results related to young men should be considered tentatively, as they are under-powered. The sample was collected within Australia, and restricted to Australian participants only. Therefore, caution is required when interpreting and generalizing results beyond the Australian context. Additionally, there is no single definition, measurement, or understanding of the nuances within sexting coercion or sexting behaviors within the current evidence-base, therefore this study's measurement and prevalence is limited by its individual wording, and the comprehension and memory of self-reporting respondents. Lastly, this sample is cisgendered and largely heteronormative, hence gender and relationship findings should be considered within those frameworks.

Despite the identified limitations, the current study contributes to research which seeks to expand understanding regarding the measurement and definition of sexting coercion, and explore the impacts of variables, such as gender and protective factors. Considering the prevalence of sexting behaviors and the technological zeitgeist, sexting is anticipated to persist, if not increase $[9,73]$. Separation between the digital and the physical world is rapidly diminishing; the digital world is no longer passive or distant from the everyday life of young people, and is becoming increasingly prominent [27]. Evidence linking sexting coercion to adverse physical, social, and psychological outcomes, and exploring constructs which empower young people to safely navigate the digital world and sexual safety, is more important than current trends which focus on criminalizing or victim-blaming $[2,66]$. This study contributes to early insights into processes associated with sexting coercion within the Australian context, and informs future exploration of protective factors.

\section{Conclusions}

As expected, findings revealed sexting coercion is associated with gender and DoS. Lower DoS increased vulnerability to conform under pressure, expressed as sexual and cultural compliance through sexting coercion, predominantly in young women. Additionally, an increased sense of self and reduced emotional fusion with others were found to mediate the relationship between gender and sexting when pressured. Results offer support for the importance of understanding psychological dimensions of what may constitute strengths (protective factors), or vulnerabilities, towards risks associated with sexting coercion. Furthermore, results highlight areas for future research to clarify nomenclature regarding the sexting coercion construct and sub-constructs. Findings hold importance for the growing development of sexting research in a digital era, and prevention strategies which mitigate sexting coercion.

Supplementary Materials: The following are available online at https:/ /www.mdpi.com/article/10 .3390/sexes2040037/s1, Supplementary S1: The Sexting Questionnaire.

Author Contributions: Conceptualization, J.L., B.K. and E.C.; Methodology, J.L., B.K., E.C. and I.F.; Formal Analysis, J.L. and I.F.; Writing-Original Draft Preparation, J.L. and B.K.; Writing-Review and Editing, J.L., B.K. and E.C.; Supervision, B.K. All authors have read and agreed to the published version of the manuscript.

Funding: This research received no external funding.

Institutional Review Board Statement: The study was conducted according to the protocols reviewed and approved by the Institutional Review Board of Deakin University, Australia (Application no. HEAG-H 96_2012).

Informed Consent Statement: Informed consent was obtained from all subjects involved in the study. 
Data Availability Statement: Data are available from the corresponding author upon reasonable request.

Conflicts of Interest: The authors declare no conflict of interest.

\section{References}

1. Klettke, B.; Hallford, D.J.; Clancy, E.; Mellor, D.J.; Toumbourou, J.W. Sexting and psychological distress: The role of unwanted and coerced sexts. Cyberpsychology Behav. Soc. Netw. 2019, 22, 237-242. [CrossRef] [PubMed]

2. Barroso, R.; Ramião, E.; Figueiredo, P.; Araújo, A.M. Abusive sexting in adolescence: Prevalence and characteristics of abusers and victims. Front. Psychol. 2021, 12, 380. [CrossRef] [PubMed]

3. Strasburger, V.C.; Zimmerman, H.; Temple, J.R.; Madigan, S. Teenagers, sexting, and the law. Pediatrics 2019, 143 , e20183183. [CrossRef] [PubMed]

4. Ross, J.M.; Drouin, M.; Coupe, A. Sexting coercion as a component of intimate partner polyvictimization. J. Interpers. Violence 2019, 34, 2269-2291. [CrossRef]

5. Drouin, M.; Ross, J.; Tobin, E. Sexting: A new, digital vehicle for intimate partner aggression? Comput. Hum. Behav. 2015, 50, 197-204. [CrossRef]

6. Lee, M.; Crofts, T. Gender, pressure, coercion and pleasure: Untangling motivations for sexting between young people. Br. J. Criminol. 2015, 55, 454-473. [CrossRef]

7. Choi, H.; Van Ouytsel, J.; Temple, J.R. Association between sexting and sexual coercion among female adolescents. J. Adolesc. 2016, 53, 164-168. [CrossRef]

8. Drouin, M.; Tobin, E. Unwanted but consensual sexting among young adults: Relations with attachment and sexual motivations. Comput. Hum. Behav. 2014, 31, 412-418. [CrossRef]

9. Cooper, K.; Quayle, E.; Jonsson, L.; Svedin, C.G. Adolescents and self-taken sexual images: A review of the literature. Comput. Hum. Behav. 2016, 55, 706-716. [CrossRef]

10. Dake, J.A.; Price, J.H.; Maziarz, L.; Ward, B. Prevalence and correlates of sexting behavior in adolescents. Am. J. Sex. Educ. 2012, 7, 1-15. [CrossRef]

11. Levine, D. Sexting: A Terrifying health risk ... or the new normal for young adults? J. Adolesc. Health 2013, 52, 257-258. [CrossRef]

12. Laird, J.J.; Klettke, B.; Hall, K.; Clancy, E.; Hallford, D. Demographic and psychosocial factors associated with child sexual exploitation: A systematic review and meta-analysis. JAMA Netw. Open 2020, 3, e2017682. [CrossRef] [PubMed]

13. Crofts, T.; Lee, M. Sexting, children and child pornography. Syd. Law Rev. 2013, 35, 85.

14. Lu, Y.; Baumler, E.; Temple, J.R. Multiple forms of sexting and associations with psychosocial health in early adolescents. Int. J. Environ. Res. Public. Health 2021, 18, 2760. [CrossRef] [PubMed]

15. Henry, N.; Powell, A. Beyond the 'Sext': Technology-facilitated sexual violence and harassment against adult women. Aust. N. Z. J. Criminol. 2015, 48, 104-118. [CrossRef]

16. Henry, N.; Powell, A. Technology-facilitated sexual violence: A literature review of empirical research. Trauma Violence Abus. 2018, 19, 195-208. [CrossRef] [PubMed]

17. Kernsmith, P.D.; Victor, B.G.; Smith-Darden, J.P. Online, offline, and over the line: Coercive sexting among adolescent dating partners. Youth Soc. 2018, 50, 891-904. [CrossRef]

18. Englander, E. Low Risk Associated With Most Teenage Sexting: A Study of 617 18-Year-Olds; Massachusetts Aggression Reduction Center Research Reports 6; Bridgewater State University: Bridgewater, MA, USA, 2012.

19. RAV. Sexting; Page; Relationships Australia Victoria (RAV): Melbourne, Australia, 2017.

20. Reed, L.A.; Tolman, R.M.; Ward, L.M. Snooping and sexting: Digital media as a context for dating aggression and abuse among college students. Violence Women 2016, 22, 1556-1576. [CrossRef]

21. Machimbarrena, J.M.; Calvete, E.; Fernández-González, L.; Álvarez-Bardón, A.; Álvarez-Fernández, L.; González-Cabrera, J. Internet risks: An overview of victimization in cyberbullying, cyber dating abuse, sexting, online grooming and problematic internet use. Int. J. Environ. Res. Public. Health 2018, 15, 2471. [CrossRef]

22. Döring, N. How is the COVID-19 pandemic affecting our sexualities? An overview of the current media narratives and research hypotheses. Arch. Sex. Behav. 2020, 49, 2765-2778. [CrossRef]

23. Mitchell, J.E.; Raghavan, C. The impact of coercive control on use of specific sexual coercion tactics. Violence Women 2021, 27, 187-206. [CrossRef]

24. Morgan, E.; Johnson, I.; Sigler, R. Gender differences in perceptions for women's participation in unwanted sexual intercourse. J. Crim. Justice 2006, 34, 515-522. [CrossRef]

25. Stanley, N.; Barter, C.; Wood, M.; Aghtaie, N.; Larkins, C.; Lanau, A.; Överlien, C. Pornography, sexual coercion and abuse and sexting in young people's intimate relationships: A european study. J. Interpers. Violence 2018, 33, 2919-2944. [CrossRef] [PubMed]

26. Krieger, M.A. Unpacking "sexting": A systematic review of nonconsensual sexting in legal, educational, and psychological literatures. Trauma Violence Abus. 2017, 18, 593-601. [CrossRef] [PubMed]

27. Ringrose, J.; Harvey, L.; Gill, R.; Livingstone, S. Teen girls, sexual double standards and 'sexting': Gendered value in digital image exchange. Fem. Theory 2013, 14, 305-323. [CrossRef] 
28. Brem, M.J.; Stuart, G.L.; Cornelius, T.L.; Shorey, R.C. A Longitudinal examination of alcohol problems and cyber, psychological, and physical dating abuse: The moderating role of emotion dysregulation. J. Interpers. Violence 2019, 36, 886260519876029. [CrossRef] [PubMed]

29. Trub, L.; Starks, T.J. Insecure attachments: Attachment, emotional regulation, sexting and condomless sex among women in relationships. Comput. Hum. Behav. 2017, 71, 140-147. [CrossRef]

30. Van Ouytsel, J.; Walrave, M.; Ponnet, K.; Heirman, W. The association between adolescent sexting, psychosocial difficulties, and risk behavior: Integrative review. J. Sch. Nurs. 2015, 31, 54-69. [CrossRef]

31. Berger, A.; Kofman, O.; Livneh, U.; Henik, A. Multidisciplinary Perspectives on attention and the development of self-regulation. Prog. Neurobiol. 2007, 82, 256-286. [CrossRef]

32. Houck, C.D.; Barker, D.; Rizzo, C.; Hancock, E.; Norton, A.; Brown, L.K. Sexting and sexual behavior in at-risk adolescents. Pediatrics 2014, 133, e276-e282. [CrossRef]

33. McDaniel, B.T.; Drouin, M. Sexting among married couples: Who is doing it, and are they more satisfied? Cyberpsychology Behav. Soc. Netw. 2015, 18, 628-634. [CrossRef] [PubMed]

34. Reyns, B.W.; Henson, B.; Fisher, B.S. Digital deviance: Low self-control and opportunity as explanations of sexting among college students. Sociol. Spectr. 2014, 34, 273-292. [CrossRef]

35. Weisskirch, R.S.; Delevi, R. "Sexting" and adult romantic attachment. Comput. Hum. Behav. 2011, 27, 1697-1701. [CrossRef]

36. Gassó, A.M.; Klettke, B.; Agustina, J.R.; Montiel, I. Sexting, mental health, and victimization among adolescents: A literature review. Int. J. Environ. Res. Public. Health 2019, 16, 2364. [CrossRef] [PubMed]

37. Hainlen, R.L.; Jankowski, P.J.; Paine, D.R.; Sandage, S.J. Adult Attachment and well-being: Dimensions of differentiation of self as mediators. Contemp. Fam. Ther. 2016, 38, 172-183. [CrossRef]

38. Sandage, S.J.; Jankowski, P.J.; Bissonette, C.D.; Paine, D.R. Vulnerable narcissism, forgiveness, humility, and depression: Mediator effects for differentiation of self. Psychoanal. Psychol. 2017, 34, 300-310. [CrossRef]

39. Skowron, E.A.; Platt, L.F. Differentiation of self and child abuse potential in young adulthood. Fam. J. 2005, 13, 281-290. [CrossRef]

40. Thorberg, F.A.; Lyvers, M. Attachment, fear of intimacy and differentiation of self among clients in substance disorder treatment facilities. Addict. Behav. 2006, 31, 732-737. [CrossRef]

41. Drake, J.R.; Murdock, N.L.; Marszalek, J.M.; Barber, C.E. Differentiation of self inventory-Short form: Development and preliminary validation. Contemp. Fam. Ther. 2015, 2, 101. [CrossRef]

42. Burri, A.; Schweitzer, R.; O'Brien, J. Correlates of female sexual functioning: Adult attachment and differentiation of self. J. Sex. Med. 2014, 11, 2188-2195. [CrossRef]

43. Murdock, N.L.; Gore, P.A., Jr. Stress, coping, and differentiation of self: A test of bowen theory. Contemp. Fam. Ther. Int. J. 2004, 26, 319-335. [CrossRef]

44. Skowron, E.; Stanley, K.; Shapiro, M. A Longitudinal perspective on differentiation of self, interpersonal and psychological well-being in young adulthood. Contemp. Fam. Ther. Int. J. 2009, 31, 3-18. [CrossRef]

45. Sheikh, F.; Koolaee, A.K.; Zadeh, M.R. The comparison of self-differentiation and self-concept in divorced and non-divorced women who experience domestic violence. Int. J. High Risk Behav. Addict. 2013, 2, 66. [CrossRef]

46. Schnarch, D.; Regas, S. The crucible differentiation scale: Assessing differentiation in human relationships. J. Marital Fam. Ther. 2012, 38, 639-652. [CrossRef] [PubMed]

47. Xue, Y.; Xu, Z.-Y.; Zaroff, C.; Chi, P.; Du, H.; Ungvari, G.S.; Chiu, H.F.K.; Yang, Y.-P.; Xiang, Y.-T. Associations of differentiation of self and adult attachment in individuals with anxiety-related disorders. Perspect. Psychiatr. Care 2018, 54, 54-63. [CrossRef] [PubMed]

48. Yousefi, N.; Kiani, M.A. The study of two psychotherapy approaches (rogers self theory and ellis rational theory) in improvement of bowen self-differentiation and intimacy. Iran. J. Psychiatry Behav. Sci. 2014, 8, 32-41. [PubMed]

49. Shaghaghi, A.; Bhopal, R.S.; Aziz, S. Approaches to recruiting 'Hard-to-Reach' populations into research: A review of the literature. Health Promot. Perspect. 2011, 1, 86-94. [CrossRef] [PubMed]

50. Skowron, E.A.; Friedlander, M.L. The differentiation of self inventory: Development and initial validation. J. Couns. Psychol. 1998, 45, 235-246. [CrossRef]

51. Skowron, E.A. Assessing Interpersonal fusion: Reliability and validity of a new DSI fusion with others subscale. J. Marital Fam. Ther. 2003, 29, 209-222. [CrossRef]

52. Tabachnick, B.G.; Fidell, L.S. Using Multivariate Statistics, 4th ed.; Allyn and Bacon: Boston, MA, USA, 2001.

53. Howell, D.C. Statistical Methods for Psychology, 8th ed.; Cengage Learning: Belmont, CA, USA, 2011.

54. Cohen, J. A power primer. Psychol. Bull. 1992, 112, 155-159. [CrossRef]

55. Chen, H.; Cohen, P.; Chen, S. How big is a big odds ratio? Interpreting the magnitudes of odds ratios in epidemiological studies. Commun. Stat. Simul. Comput. 2010, 39, 860-864. [CrossRef]

56. Iacobucci, D. Mediation analysis and categorical variables: The final frontier. J. Consum. Psychol. 2012, 22, 582-594. [CrossRef]

57. Preacher, K.J.; Hayes, A.F. Asymptotic and resampling strategies for assessing and comparing indirect effects in multiple mediator models. Behav. Res. Methods 2008, 40, 879-891. [CrossRef] [PubMed]

58. IBM Corp. IBM SPSS Statistics for Windows; IBM Corp.: Armonk, NY, USA, 2016.

59. Hayes, A.F. Introduction to Mediation, Moderation, and Conditional Process Analysis: A Regression-Based Approach; Methodology in the social sciences; The Guilford Press: New York, NY, USA, 2013. 
60. Baron, R.M.; Kenny, D.A. The moderator-mediator variable distinction in social psychological research: Conceptual, strategic, and statistical considerations. J. Pers. Soc. Psychol. 1986, 51, 1173-1182. [CrossRef]

61. Cumming, G. The new statistics: Why and how. Psychol. Sci. 2014, 25, 7-29. [CrossRef] [PubMed]

62. MacKinnon, D.P. Introduction to Statistical Mediation Analysis; Multivariate applications; Lawrence Erlbaum Associates: Mahwah, NJ, USA, 2008.

63. Field, A. Discovering Statistics Using SPSS: (and Sex and Drugs and Rock " $n$ " Roll): Deakin University Library Search, 3rd ed.; SAGE Publications: London, UK, 2009.

64. Ferguson, C.J. An effect size primer: A guide for clinicians and researchers. Prof. Psychol. Res. Pract. 2009, 40, 532-538. [CrossRef]

65. Morelli, M.; Bianchi, D.; Baiocco, R.; Pezzuti, L.; Chirumbolo, A. Not-allowed sharing of sexts and dating violence from the perpetrator's perspective: The moderation role of sexism. Comput. Hum. Behav. 2016, 56, 163-169. [CrossRef]

66. Ollis, D. The power of feminist pedagogy in australia: Vagina shorts and the primary prevention of violence against women. Gend. Educ. 2017, 29, 461-475. [CrossRef]

67. Howard, D.E.; Beck, K.; Kerr, M.H.; Shattuck, T. Psychosocial correlates of dating violence victimization among latino youth. Adolescence 2005, 40, 319-331. [PubMed]

68. Holt, T.J.; Bossler, A.M.; Malinski, R.; May, D.C. Identifying predictors of unwanted online sexual conversations among youth using a low self-control and routine activity framework. J. Contemp. Crim. Justice 2016, 32, 108-128. [CrossRef]

69. Powell, A.; Henry, N. Sexual Violence in a Digital Age; Palgrave studies in cybercrime and cybersecurity; Palgrave Macmillan: London, UK, 2017.

70. Cox, E.; Leung, R.; Baksheev, G.; Day, A.; Toumbourou, J.W.; Miller, P.; Kremer, P.; Walker, A. Violence prevention and intervention programmes for adolescents in australia: A systematic review. Aust. Psychol. 2016, 51, 206-222. [CrossRef]

71. Walsh, A.; Peters, T. NAPCAN's "growing respect": A whole-of-school approach to violence prevention and respectful relationships. Redress 2011, 20, 16

72. George, A.S.; Amin, A.; de Abreu Lopes, C.M.; Ravindran, T.K.S. Structural determinants of gender inequality: Why they matter for adolescent girls' sexual and reproductive health. BMJ 2020, 368, 16985. [CrossRef]

73. Madigan, S.; Ly, A.; Rash, C.L.; Van, J.O.; Temple, J.R. Prevalence of multiple forms of sexting behavior among youth: A systematic review and meta-analysis. JAMA Pediatr. 2018, 172, 327-335. [CrossRef] [PubMed] 